\title{
ASORTIMAN PROIZVODA U PROREDNOJ DRVNOJ MASI ŠUMSKIH KULTURA BIJELOG BORA (Pinus sylvestris L.)*
}

\section{Wood assortment in thinning raw material of scots pine forest plantations}

(Pinus sylvestris L.)

\author{
Jusuf Musić ${ }^{1}$
}

\begin{abstract}
In order to improve managing of the established forest plantations in Bosnia and Herzegovina, this paper deals with the practical aspect of the problem, and subsequents verification of the exact assortment of the forest wood products in the increasingly thinning raw material of the Scots pine forest plantations. The size and the mode of influence of the breast-height diameter and the technical quality classes at the percentage participation of assortments in woody mass were analyzed with the purpose to create an adequate table of the wood assortment.
\end{abstract}

Kew words: Scots pine, forest plantations, thinning, forest wood products, tables of assortments.

\section{Izvod}

U cilju unapređenja gazdovanja sa podignutim šumskim kulturama u Bosni i Hercegovini ovaj rad se bavi praktičnim aspektom problema, odnosno utvrđivanjem realnog asortimana šumskih drvnih proizvoda $u$ drvnom masi koja se dobiva provođenjem prorednih sječa $u$ kulturama bijelog bora. Pored toga u okviru rada istraživana je veličina i način uticaja prsnog prečnika i tehničkih kvalitetnih klasa na procentualno učešće pojedinih sortimenata u drvnoj masi stabla radi izrade adekvatnih sortimenatnih tablica.

Ključne riječi: bijeli bor, šumske plantaže, prorede, šumski drvni proizvodi, sortimentne tablice.

\section{Uvod - Introduction}

Prema evidenciji od 31.12.1990. god. u BiH registrovano je postojanje 125479 ha raznih šumskih kultura u državnoj svojini. Nasuprot tome, podatak da je samo u

\footnotetext{
* Rad prezentiran na III simpoziju poljoprivrede, veterinarstva, šumarstva i biotehnologije sa međunarodnim učešćem Strategija razvoja domaće proizvodnje, 28 - 30 septembar/rujan 2005. Sanski Most

${ }^{1}$ Šmarski fakultet Univerziteta u Sarajevu - Faculty of Forestry University of Sarajevo
} 
periodu od 1965. do 1991. godine podignuto 208464 ha šumskih kultura (MEKIĆ, 1999), dovoljno govori o tome kakav je do sada bio odnos šumarske prakse prema podignutim kulturama. Neadekvatan izbor vrsta za odgovarajuća staništa, loš genetski materijal, nepoznate provinijencije, uz izostanak mjera njege, rezultirali su nestajanjem mladih kultura, s jedne, te prilično lošim stanjem preostalih, s druge strane. Činjenica je da šumske plantaže uz pažljivo i znalačko planiranje, upravljanje i korištenje predstavljaju efikasan način proizvodnje šumskih drvnih sortimenata na ograničenim površinama te $u$ tom smislu mogu umnogome pomoći smanjenju degradacije i deforestacije prirodnih šuma.

Izostanak neophodnih mjera njege u našim kulturama uglavnom se pravda negativnim ekonomskim efektima realizacije prorednih sječa, odnosno finansijskim gubicima koji se, u uslovima samofinansiranja šumarstva, moraju pokrivati iz tekućeg prihoda ostvarenog od prodaje drvnih sortimenata iz visokih šuma, a koji je ograničen i nedostatan. Ipak, u okviru dugoročnog cilja gospodarenja šumama - maksimiranje ukupne vrijednosti svih funkcija šume (proizvodne i općekorisne) primjereno stanišnim potencijalima - proredne sječe (prorede) predstavljaju ekonomski opravdanu biološku investiciju jer neposredno doprinose povećanju kvaliteta i vrijednosti prirasta.

U vezi sa rečenim, ovaj rad se bavi praktičnim aspektom problema, odnosno naučno dokumentovanim utvrđivanjem naturalnih pokazatelja na kojima se temelje godišnji planovi, obračuni i ekonomski bilansi rada na njezi-prorjeđivanju zapuštenih nasada bijelog bora.

\section{Područje istraživanja - Research area}

Istraživanja su obavljena na području JP "Unsko-sanske šume”, ŠU "Cazin, Bužim i Velika Kladuša". U ukupnoj površini šuma i šumskog zemljišta kojima gospodari ova šumska uprava, šumske plantaže i kulture participiraju sa više od $25 \%$, što je više nego dovoljan razlog da se dosadašnja praksa promijeni $u$ intenzivno gospodarenje postojećim šumskim plantažama i kulturama.

Kao osnovni metodološki reper poslužili su, u odnosu na sve ostale šumske kulture, najzastupljeniji šumski nasadi bijelog bora. Za te šumske kulture izabrana su dva odjeljenja u šumskoj plantaži "Dubrave", koja svojom ekologijom i sastojinskim strukturama najbolje reprezentiraju spomenute nasade u cjelini. Međutim, objektivno dijagnosticirani rezultati ovih istraživanja su primjenljivi za sve nasade bijelog bora sa istom ili sličnom ekologijom i sastojinskim strukturama, neovisno od područja.

Šumska plantaža "Dubrave" (slika 1) osnovana je u periodu od 1961. do 1968. god. na platou iznad kanjona rijeke Une i na površini od oko 500 ha. Prije osnivanja plantaže to je bilo napušteno poljoprivredno područje, koje je stanovništvo okolnih sela (Brekovica, Osredak, Vrelo, Kula i dr.) koristilo za ispašu stoke. Geološku podlogu čine jedri i kristalasti dolomiti na kojima se smjenjuju različiti varijiteti luvisola (tipični i akrični). S obzirom da su veoma stara, ova su tla jako isprana i 
zakiseljena (reakcija tla u vrijeme pedološke analize kretala se od veoma kisele do kisele), uz nizak stepen zasićenosti bazama i umbričnim humusnim horizontom.

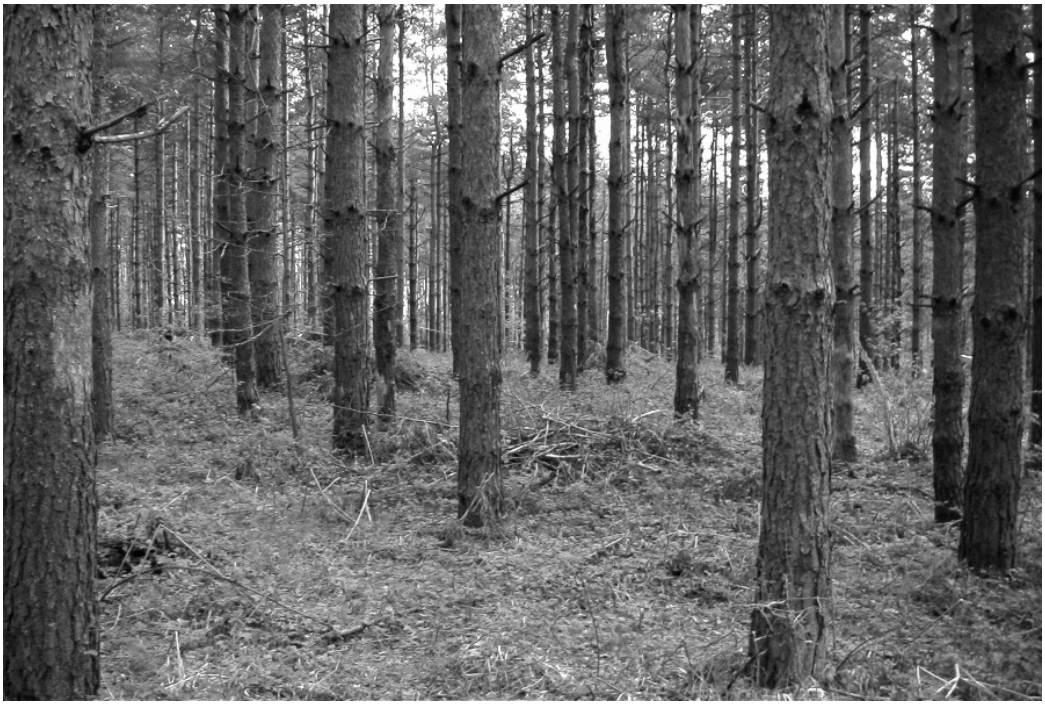

Slika 1. Šumska plantaža «Dubrave» nakon prorede

Photo 1. Forest plantation «Dubrave» after thinning

Ipak, ovakva tla posjeduju solidan potencijal za podizanje šumskih četinarskih nasada, ako se mehaničkom obradom i fertilizacijom otklone glavni limitirajući faktori rasta, što je prije podizanja plantaže "Dubrave" uglavom i učinjeno.

\section{Metodika i rezultati istraživanja - Method and results of research}

\subsection{Doznaka stabala - Marking of trees}

U šumskoj plantaži "Dubrave" provedena je u osnovi Schädelinova (1942) selektivna proreda, uz uvažavanje promjena u upravljanju čistim borovim sastojinama koje su se desile u zadnjih 10 godina, sa ciljem da se zadovolji veća prirodnost i poveća biološki diverzitet. Osnovni principi ovog metoda su: (1) toleriranje i potpomaganje lišćarskih vrsta unutar borovih sastojina, (2) promjena koncepta maksimalizacije prirasta u koncept produkcije visokokvalitetnog drveta, (3) tolerisanje zaostalih dubećih i ležećih mrtvih stabala u cilju potpomaganja opstanka organizama ovisnih o toj sredini.

Sama doznaka stabala provedena je u dvije sukcesivne faze. U prvoj fazi je u okviru svake proredne ćelije (grupe stabala koja se izdvaja od svoje okoline po tome što svi njeni članovi stoje prema stablima aspirantima $\mathrm{u}$ neposrednim ili posrednim društvenim odnosima) izvršen izbor i označavanje tzv. aspiranata, odnosno stabala koja se s obzirom na kvalitet debla i prirast ističu među drugim stablima jedne proredne ćelije. 
U drugoj fazi izvršena je doznaka stabala za sječu. Doznaka je obuhvatila samo ona stabla koja svojim položajem i rastom predstavljaju najjače konkurente odabranim aspirantima (stablima budućnosti) i to uglavnom jedno, u rijeđim slučajevim dva takva stabla.

\subsection{Uzorak - Sample}

U predmetnim istraživanjima primjenjen je metod tzv. "malog uzorka", pri čemu su prethodno definisane četiri tehničke kvalitetne klase i četiri debljinske klase, te se za svaku debljinsko-kvalitetnu kategoriju slučajno vršio izbor predstavnika na terenu. Ukupno je izabrano 140 stabala (65 stabala u odjeljenju 26 i 75 stabala u odjeljenju 30), što u odnosu na ograničenu debljinsku strukturu i ekološke uslove objekta istraživanja u potupnosti zadovoljava kriterije određivanja veličine uzorka po spomenutom postupku. Prilikom izbora stabala predstavnika vodilo se računa o tome da u uzorku budu podjednako zastupljena stabla iz svih dijelova odjeljenja, odnosno sa cijele njegove površine.

Najviše i najniže debljinske klase (ispod 15 i iznad $35 \mathrm{~cm}$ ) nisu obuhvaćene jer se radi o stablima koja su u debljinskoj strukturi odjeljenja, a samim tim i u strukturi doznačene drvne mase, zastupljena u izrazito malom broju, odnosno kao pojedinačna stabla. Ispuštene klase u ukupnoj zapremini doznačene drvne mase participiraju sa svega 2,6 \%. U tom pogledu uzorak u najvećoj mogućoj mjeri, odnosno sa 97,4 \% reprezentuje doznačenu drvnu masu.

\subsection{Asortiman šumskih drvnih proizvoda - Assortment of the forest wood products}

Mjerenje i razvrstavanja drvne mase pri krojenju odnosno sortiranju oblog drveta obavljeno je po još uvijek važećem JUS-u za šumske drvne sortimente.

Prilikom iskrajanja debla u šumske drvne sortimente konzekventno se slijedio princip "maksimalne ukupne vrijednosti sortimenata jednog stabla". Nakon krojenja stabala na šumske drvne sortimente izračunate su zapremine pojedinih sortimenata (bez kore) i to na način koji je propisan pomenutim standardom.

Sva premjerena i iskrojena stabla razvrstana su po tehničkim kvalitetnim klasama. Za kvalitetnu klasifikaciju stabala korišćeni su kriteriji tehničke klasifikacije stabala bijelog i crnog bora u visokim šumama (MATIĆ, V. ET AL. 1971 i MATIĆ, V. 1977), s tim da je i za stabla tanja od $30 \mathrm{~cm}$ formirana i II tehnička kvalitetna klasa (Pavlič, 1999), budući da su u pomenutoj klasifikaciji za ova stabla formirane samo I, III i IV tehnička klasa.

Unutar svake tehničke kvalitetne klase formirane su debljinske klase širine $5 \mathrm{~cm}$. Za svaku debljinsku klasu sabrane su zapremine svakog pojedinog sortimenta i zapremine krupnog drveta stabla sa korom. Procentualno učešce pojedinih sortimenata u zapremini krupnog drveta stabla sa korom izračunato je za svaku debljinsku klasu na osnovu sume njegove zapremine i sume zapremina krupnog drveta svih stabala koja pripadaju toj debljinskoj klasi. 
Na primjer, za celulozno drvo procentualno učešće u određenoj tehničkoj kvalitetnoj i debljinskoj klasi je izračunato na slijedeći način:

$$
(\% \mathrm{CD})=\frac{\sum \text { zapremina celuloznog drveta }}{\sum \text { zapremina krupnog drveta sa korom }}
$$

$\mathrm{Na}$ osnovu izračunatih zapremina pojedinih vrsta sortimenata određeno je njihovo prosječno procentualno učešće $u$ drvnoj masi krupnog drveta po debljinskim i tehničkim kvalitetnim klasama klasama i prikazano u tabelama 1, 2, 3 i 4.

Tabela 1. Prosječno procentualno učešće sortimenata u drvnoj masi krupnog drveta stabla

Table 1. Average percent ratio of wood assortments in large-wood mass of tree

\begin{tabular}{|c|c|c|c|c|}
\hline & \multicolumn{4}{|c|}{$\begin{array}{c}\text { Procentualno učešće sortimenata po } \\
\text { debljinskim klasama }(\%)\end{array}$} \\
\hline & $15-20$ & $20-25$ & $25-30$ & $30-35$ \\
\hline Trupci za rezanje I klase & - & - & - & 8,66 \\
\hline Trupci za rezanje II klase & - & 18,84 & 41,44 & 50,94 \\
\hline Trupci za rezanje III klase & - & 3,13 & 6,46 & 10,64 \\
\hline Stubovi za vodove & 20,11 & 19,47 & - & - \\
\hline Rudničko drvo & 42,62 & 27,46 & 23,43 & 6,48 \\
\hline Celulozno drvo & 15,88 & 10,54 & 7,08 & 5,37 \\
\hline $\begin{array}{l}\text { Drvo za drvene ploče } \\
\text { (oblice } 1 \mathrm{~m} \mathrm{~L} \text { ) }\end{array}$ & 1,24 & 2,12 & 2,26 & 1,26 \\
\hline Drvo za drvene ploče & & & & \\
\hline (ostaci $0,5 \mathrm{~m}$ i više) & 1,26 & 1,10 & 1,55 & 1,50 \\
\hline Otpadak + kora & 18,89 & 17,34 & 17,78 & 15,15 \\
\hline Iskorišćenje & 81,11 & 82,66 & 82,22 & 84,85 \\
\hline$\Sigma$ & 100 & 100 & 100 & 100 \\
\hline
\end{tabular}

I tehnička klasa 
Tabela 2. Prosječno procentualno učešće sortimenata u drvnoj masi krupnog drveta stabla

Table 2. Average percent ratio of wood assortments in large-wood mass of tree

\begin{tabular}{|c|c|c|c|c|}
\hline & \multicolumn{4}{|c|}{ II tehnička klasa } \\
\hline & \multicolumn{4}{|c|}{$\begin{array}{c}\text { Procentualno učešće sortimenata po } \\
\text { debljinskim klasama (\%) }\end{array}$} \\
\hline & $15-20$ & $20-25$ & $25-30$ & $30-35$ \\
\hline Trupci za rezanje I klase & - & - & - & - \\
\hline Trupci za rezanje II klase & - & 18,04 & 35,82 & 42,05 \\
\hline Trupci za rezanje III klase & - & 2,95 & 5,28 & 8,38 \\
\hline Stubovi za vodove & 2,78 & - & - & - \\
\hline Rudničko drvo & 55,40 & 40,57 & 21,33 & 17,64 \\
\hline Celulozno drvo & 20,47 & 17,62 & 16,60 & 14,77 \\
\hline Drvo za dr. ploče ( $1 \mathrm{~m})$ & 2,06 & 2,27 & 2,61 & 1,26 \\
\hline Drvo za dr. ploče ( $0,5 \mathrm{~m}$ i više) & 1,22 & 0,8 & 1,27 & 0,44 \\
\hline Otpadak + kora & 18,07 & 17,75 & 17,09 & 15,46 \\
\hline Iskorišćenje & 81,93 & 82,25 & 82,91 & 84,54 \\
\hline$\Sigma$ & 100 & 100 & 100 & 100 \\
\hline
\end{tabular}

Tabela 3. Prosječno procentualno učešće sortimenata u drvnoj masi krupnog drveta stabla

Table 3. Average percent ratio of wood assortments in large-wood mass of tree

III tehnička klasa

\begin{tabular}{|c|c|c|c|c|}
\hline & \multicolumn{4}{|c|}{$\begin{array}{c}\text { Procentualno učešće sortimenata po } \\
\text { debljinskim klasama }(\%)\end{array}$} \\
\hline & $15-20$ & $20-25$ & $25-30$ & $30-35$ \\
\hline Trupci za rezanje I klase & - & - & - & - \\
\hline Trupci za rezanje II klase & - & 17,44 & 22,66 & 37,76 \\
\hline Trupci za rezanje III klase & - & - & 9,41 & 10,14 \\
\hline Stubovi za vodove & - & - & - & - \\
\hline Rudničko drvo & 46,52 & 30,38 & 20,38 & 16,48 \\
\hline Celulozno drvo & 30,66 & 29,32 & 26,45 & 16,23 \\
\hline Drvo za dr. ploče (1 m) & 1,64 & 2,04 & 1,32 & 1,43 \\
\hline Drvo za dr. ploče $(0,5 \mathrm{~m}$ i više $)$ & 1,21 & 2,12 & 1,11 & 1,06 \\
\hline Otpadak + kora & 19,97 & 18,70 & 18,67 & 16,90 \\
\hline Iskorišćenje & 80,03 & 81,30 & 81,33 & 83,10 \\
\hline$\Sigma$ & 100 & 100 & 100 & 100 \\
\hline
\end{tabular}


Tabela 4. Prosječno procentualno učešće sortimenata u drvnoj masi krupnog drveta stabla

Table 4. Average percent ratio of wood assortments in large-wood mass of tree

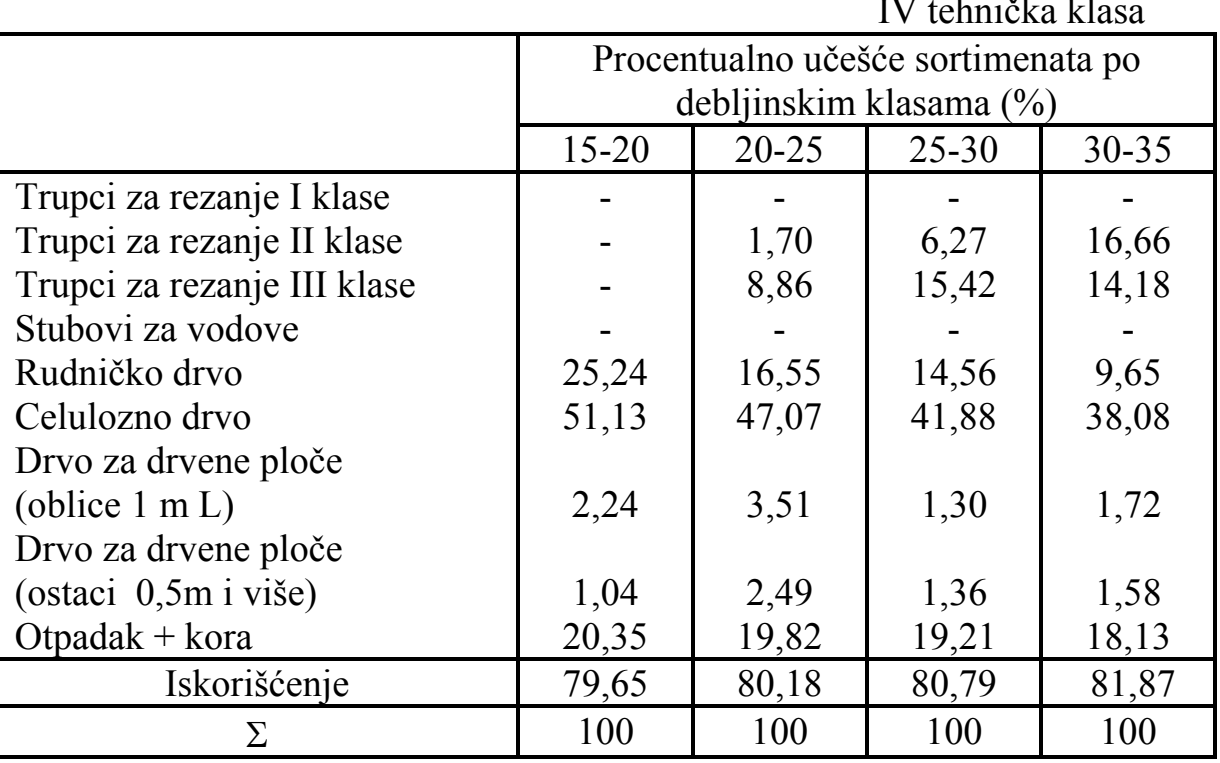

\section{Zaključak - Conclusion}

$\mathrm{Na}$ osnovu dobivenih rezultata provedenih istraživanja izdvaju se slijedeći bitniji zaključci:

1. Analiza ovisnosti procentualnog učešća sortimenata od prsnog prečnika i tehničke kvalitetne klase pokazuje da su navedeni uticaji logični i da su po svom obliku slični rezultatima do kojih su došli drugi autori. Iako za bijeli bor u BiH do sada nisu istraživani navedeni uticaji, rezultati pokazuju da su oni za istovrsne sortimente po svom obliku slični rezultatima do kojih su, u okviru svojih istraživanja, došli PAVlič, J. (1973) za smrču, PRolić, N. (1975) za jelu te VUKMIROVIĆ, V. (1971) za bukvu. Drugim riječima, prsni prečnik stabla i tehnička kvalitetna klasa imaju sličan uticaj na procentualnu zastupljenost istovrsnih sortimenata bez obzira na vrstu drveća.

2. Imajuću u vidu činjenicu da procentualno učešće pojedinih sortimenata drvnoj masi stabla zavisi primarno i presudno od prsnog prečnika i tehničke kvalitetne klase, a od ostalih uticajnih faktora samo sekundarno, može se zaključiti da se dobiveni rezultati mogu koristiti kao sortimentne tablice sa prilično velikom pouzdanošću (sigurnošću) za opisane i slične sastojinske i stanišne uslove te sa 
prihvatljivom sigurnošću za ostale stanišne i sastojinske prilike u kulturama i plantažama bijelog bora, za istraženi interval variranja prsnog prečnika od 15 do $35 \mathrm{~cm}$.

3. Polazeći od činjeničnog stanja naših kultura s jedne, te izražene potrebe ali i obaveze za njihovom njegom i prorjeđivanjem s druge strane, rezultati ovog rada predstavljaju jednu od neophodnih polaznih osnova za kvalitetno gazdovanje našim kulturama bijelog bora.

\section{Literatura - References}

1. Jugoslovenski standard za oblast šumarstva-JUS. Jugoslovenski Zavod za standardizaciju.Beograd (D.A0.101， 1969.;D.B0.020,1969.; D.B0.022， 1984.; D.B1.023，1980.; D.B2.020，1982.; D.B4.029, 1979.; D.B5.020，1984.; D.B5.025, 1984.)

2. Matić, V. ET AL. (1971): Stanje šuma u Bosni i Hercegovini prema inventuri šuma na velikim površinama u 1964.-1968. godini. Šumarski fakultet i Institut za šumarstvo. Posebna izdanja, broj 7. Sarajevo.

3. MATić, V. (1977): Metodika izrade šumskoprivrednih osnova za šume u društvenoj svojini na području SR BiH. Šumarski fakultet i Institut za šumarstvo. Posebna izdanja, broj 12. Sarajevo

4. Mekić, F. (1999): Sadašnje stanje i mogućnosti povećanja kvaliteta naših šuma. Savjetovanje Šumarstvo Federacije Bosne i Hercegovine, Zbornik radova. Federalno Ministrstvo poljoprivrede, vodoprivrede i šumarstva Bosne i Hercegovine, str.34-48.

5. PAVLIČ, J. (1973): Istraživanje zavisnosti procentualnog učešća sortimenata smrče od debljine, visine i kvaliteta stabla. Radovi Šumarskog fakulteta i Instituta za šumarstvo u Sarajevu, knj.17., sv.1-3.

6. PAVLIČ, J.(1999): Metodika premjera i registrovanja podataka u jednodobnim šumskim zasadima smrče (Picea abies Karst.), bijelog bora (Pinus sylvestris L.) i crnog bora (Pinus nigra Arn.) u Bosni i Hercegovini. Radovi Šumarskog fakulteta u Sarajevu, br.1., knjiga XXIX, str. 33-60.

7. SCHÄDELIN, W. (1942): Die auslesedurchforstung als erziebhungsbetrieb höchster wertleistung. Prevod Pataky, Lj., 1956, Narodni šumar, Sarajevo

8. VuKMIROVIĆ, V.(1971): Istraživanje učešća sortimenata bukve u čistim i mješovitim bukovim sastojinama u Bosni. Sortimentne tablice. Radovi Šumarskog fakulteta i Instituta za šumarstvo u Sarajevu, knjiga 14., sv.4-6. str.33-66. 


\section{Summary - Sažetak}

In a broader sense, forest plantations represent every artificially established forest by way of seeding and/or planting. All forest experts agree that establishing and caring for forest plantations should be carried out with an increased intensity because the long-term aim of forest management has economic and environmental justification. This work therefore, deals with the practical aspect of this problem, and accordingly with verification of the exact assortment of the forest wood products in the increasingly thinning raw material of the Scots pine forest plantations.

The research was carried out at the territory of the "Unsko-sanske sume", the timber management company at the forest plantation "Dubrave" near Cazin.

In this plantation we conducted the Schädelin's selective thinning in two phases. In the first phase we selected «future trees», and in the second we marked the trees for removal from the plantation. For the removal we only marked those trees, which represented the strongest concurrence to the chosen «future trees», based on their place and growth in the plantation. In majority of the cases we only marked one tree for removal and rarely two. After cutting of the marked trees, we formed a sample of 140 trees by random choice for determining the percent of wood assortment ratio in the total mass in relation to diameter at the brest height $(\mathrm{DBH})$ and technical quality class. The influence of the considered factors at the percentage ratio of the wood assortment was determined by regression analysis and we came up with appropriate tables.

The analysis shown that the surveyed elements have logical impact and that they are approximate to results of other authors. The results may be used as assortment tables with very good accuracy for description of similar stand and habitat conditions, and with acceptable accuracy for other stands and habitat conditions in plantations of Scotch pine for the surveyed span of the brest diameter between 15 and $35 \mathrm{~cm}$. 